\title{
Chapter 7 \\ Research Services
}

This chapter looks at the nature of research services in parliaments. As we have seen from the previous chapters, the distinction with information (or reference) services is not a hard and fast one and it can be argued that there is a trend for convergence between the two. However, the essence of a research service is that it will provide subject specialised policy analysis and briefing to parliamentarians and is likely to be providing longer, more substantial briefings than those provided by information services.

\section{What is a Parliamentary Research Service?}

Not all parliaments have a research service and where there is one it is not necessarily in the same parliamentary department as the library and information service. ${ }^{11}$ A survey of IFLA section members in $2006^{12}$ showed that in about half of cases where the parliament had a research service, the library and the research service were in the same department. Whatever the organisational differences, there are varying ways in which the research service and the library relate to each other, from full integration to functioning almost entirely as separate entities and variants in between. And whatever the organisational arrangements, for a fully effective service to be provided to users it is important that the library and the research service have close working relationships. The evidence from the survey shows that cooperation will tend to be closer if the library and the research service are organisationally part of the same department. But it also shows that any organisational arrangement can be made to work and that being organisationally linked does not necessarily mean that cooperation will be close. There can be a tension between librarians and researchers: this is something that is regularly reported from parliaments.

\footnotetext{
${ }^{11}$ This fact is reflected in the descriptive, but somewhat cumbersome title of the IFLA section: 'Library and Research Services for Parliaments'

12 See footnote 6
} 
Effective organisations will ensure that each understands the others role and how they need to cooperate to provide a seamless service for users which complement rather than duplicate each other.

As well as these organisational differences there are huge variations in the size of research services and as a result, in the scale and specialisation of services they are able to provide. But whatever the size, the reasons for having a research service and their essential characteristics will have a lot in common.

Why have a research service? In many parliaments political parties will have research staff and individual parliamentarians may also employ one or more researchers. Such staff will support the ideology and policy of the party or parliamentarian they work for. A parliamentary research service will provide an independent non-partisan service for all parliamentarians. Both groups have a valuable role to play and parties and individual parliamentarians are always likely to feel the need to consult and discuss policy issues with staff of their own political persuasion. However, a parliamentary service provides a number of benefits. A politically impartial service can provide advice and analysis in which, if it is functioning well, parliamentarians of all parties can have confidence and the analysis and factual briefing it provides will be generally accepted as accurate. It can provide the contrary arguments to those likely to be received from political advisors, which can be useful in anticipating criticisms of a given policy and ensuring that it is robust. It can rely on a collective memory and can call on the collective knowledge and experience of all those who work within it. It can provide systemised access to reliable sources.

But how to define what a parliamentary research service is? A brief definition is that it provides specialist active advice and analysis to parliamentarians. The provision of reference or information services frequently entails searching out materials and information on a given subject and examining their relevance to the question asked. But the evaluation process usually stops there, with the selected materials being passed on to the enquirer for further study and evaluation. In a legislative research service however, the analyst completes the evaluation process, assesses the data and in so doing creates a new value added information 
product. Another way of looking at it is to say that a research enquiry is one where subject specialist knowledge is needed to provide a good response, as distinction from a reference enquiry where the skills needed to respond will be more search skills rather than subject knowledge skills. So a 'research' response can in fact be a very short oral briefing.

The skilled researcher will provide an unbiased analysis which is likely to be a synthesis from a number of sources and will do so using his or her specialist knowledge. The term 'research' in a parliamentary setting has far different connotations than it does in an academic setting. Academic research tends to convey notions of pure primary research, or long-lasting endeavours to discover truth and fundamental relationships in society for the purpose of advancing knowledge and understanding. Research for a legislature is more applied in nature, seeking to draw on a wide range of existing knowledge and then to synthesise it in a form that is useful for busy parliamentarians and apply it to the understanding and solution of specific problems. Indeed, some would question whether then term 'research' is the best one to use at all, at least unless it is qualified in some way. 'Policy analysis' is an alternative term that is often used and which perhaps gives a more accurate idea of what is involved. However, the terms 'research' and 'researcher' are in general use and will continue to be used here.

A useful concept to apply to the activities of a legislative researcher is that of a 'broker' of information: constantly scanning the world of outside knowledge for those findings and concepts that will shed light on the nature of public policy problems and then recasting those concepts into terms that can be more readily used in the legislature. The 'research broker' brings together the world of ideas and the world of action. The broker is comfortable in both worlds and is 'bi-lingual', that is, able to speak the languages of both research and policy fluently. The broker will also be skilled at understanding and analysing the different policy approaches which may be offered as a solution to any given problem in society and explaining these different approaches in a politically neutral manner. The broker needs to be aware that issues may be reported and discussed in the media in a way that demonstrates lack of proper knowledge and understanding of the issues. The broker needs to recognise that even if discussion is ill-informed it may still set the tone for public de- 
bate and discussion and that politicians are often driven by the headlines in today's newspaper to a greater extent than perhaps they should be. The legislative researcher should take account of that, while producing information and analysis which is free of bias and demonstrates a proper understanding of the subject.

The concept of the research broker also reflects the fact that time is limited for parliamentarians who often seek analysis to tight deadlines; deadlines which might seem impossible in many academic environments. The broker must understand that his or her role is that of agent: assisting the legislature in obtaining and using information needed to make sound public policy. It is important that this making of policy is not seen as a process that comes to an end once a particular piece of legislation has been passed into law and implemented. Increasingly parliamentarians are interested in the process of examining how legislation is working in practice and whether it is achieving what it was hoped it would achieve. Because of its practical orientation, policy analysis is also more concerned with concrete implementation concerns and administrative feasibility than is academic research. Political constraints are also brought from the periphery of the discussion to play a more central role in the analysis than in more academic undertakings.

The concept of assisting the legislature to make sound public policy does not, however, mean that anything like a single 'research' view on a particular issue will emerge. A parliamentary research service should not be likened to a committee of enquiry set up to examine and make recommendations on some issue of the day. Different members of the legislature will hold a range of views on any issue and may or may not use the work of the research service to support those views. The most obvious divide in most parliaments will be between the party or parties which support the government currently in power and those that do not. Government supporters will be more likely to seek evidence supporting the policies of the government while supporters of opposition parties will be aiming to find fault with it or to seek alternative policy solutions. But divisions along party lines are, of course, not the only ones the researcher has to be aware of. Parliamentarians will not necessarily support the policies of the party they belong to on all issues, for example if they have a strong constituency interest in an alternative policy. And there are 
many topics which may be highly controversial social or moral issues where the divisions do not lie between the parties. On other occasions there may be a broad consensus on the policy direction between parties, but scope for considerable discussion and disagreement on the best way of implementing it. In all these cases the support of the research service may be sought by parliamentarians.

For a legislative research service to be fully effective it needs to be interdisciplinary in nature. Many policy issues cannot be solved simply within a single discipline. Policy on crime, for example, clearly needs to involve lawyers, but if it only involves lawyers and not, for example, education specialists and economists it is likely to be a less effective policy. It will also not be effective unless it has an understanding of the political constraints and policy principles under which governments operate. The parliamentary research service may not have the resources to ensure the interdisciplinary breadth and depth required by the modern legislature and this may be a reason for outsourcing some research requests. But this will only work if the organisations concerned understand the specialised needs of parliamentarians and the timescales within which they operate.

\section{Research outputs}

An effective parliamentary research service needs to be both proactive and reactive. That is to say, it needs to anticipate the needs of parliamentarians and respond to them. To put it another way, there will generally be some combination of making research products generally available to parliament (proactive) and responding to requests from individual parliamentarians (reactive). (This distinction is discussed in more detail in chapter 5.) A further important form of output in many research services will be supporting the work of committees through providing background research and information. In some parliaments this is a core part of the work of the research service: in others it is more marginal. But generally it has been of growing importance in recent years.

Anticipating needs means several things; It means that researchers need to be aware of the background to legislation which is scheduled to be 
debated and aware of other policy issues which are likely to come up for public discussion. These issues may be the government's own agenda, but may also be issues which are forced on parliamentarians and the government, for example because they have received a lot of attention in the media, and to which, as a result, parliamentarians need to be able to respond. In order to be in a position to respond to issues as they arise researchers need to have both a good knowledge of their subject and familiarity with and access to the key sources of information and documentation as well as good contacts with officials and others working in the same policy area. This enables researchers to produce research documents which are made generally available. The nature of these documents varies from parliament to parliament, and the same research service may produce different kinds of output to meet different needs. On one hand, there may be substantial and weighty research documents analysing the background to and contents of a piece of legislation or some current political issue. On the other, there may be brief notes along the lines of Frequently Asked Questions on specific topics of current interest. Such materials may be made available as printed documents or as documents on the parliamentary intranet which users can download. Most likely will be a combination of these.

The reactive part of the work involves responding to individual requests from individual parliamentarians. The scope for these is potentially very broad and is likely to vary according to how the parliament functions. They may range from substantial requests for work on a policy issue the parliamentarian has an interest in, to quick briefings in anticipation of a media appearance, or help with a local issue involving the parliamentarian's constituency.

Many parliaments report a shift in the balance of research work from reactive to proactive over recent years. There are a number of reasons for this but the main ones are the development of intranets in most parliaments and the development of the internet. If there is a parliamentary intranet then the library and research service will wish to have a strong presence on it and make much of its output available in that way. This means that parliamentarians and their staff may well be able to find the answer to their query from material made available on the parliamentary intranet, thus not needing to place an individual enquiry. Putting material 
on the internet can be useful for times when parliamentarians and their staff do not have access to the intranet and can also be seen as a contribution to public debate.

However, it is important not to overemphasise this shift, as was discussed in chapter 5. Parliamentary research services have always depended on the collective expertise and experience of the people who work for them. This is the expertise that is in peoples' heads. But research services will have gathered collections of material to provide quick access to useful sources, whether paper or electronic. They will also have filed previous research output so that material can readily be reused and updated when needed. What has changed is that it is much easier and more beneficial to users to make that expertise in the form of written material available to any user with access to the parliamentary intranet. It is important that the library services are aware of new resources so they can understand what is available for the benefit of users.

There is a potential downside to this however. If research output is readily available over the intranet, then the level of personal contact between parliamentarians (or their staff) and researchers will be reduced. This means that there is a risk that researchers, and other parliamentary staff, will have less direct knowledge of the needs of users because they have less direct contact with them. They may spend time producing material which does not meet the needs of parliamentarians. This question of understanding and assessing user needs is covered more fully in Chapter 9, but ways round this problem include ensuring that intranet usage is effectively monitored, and doing periodic surveys of users.

\section{Organisation}

Research services vary so much in size that it is impossible to generalise or to be prescriptive about organisation. Clearly a service with 100 people or more will have a greater need to think about organisation than one with only one or two researchers. It also makes a difference according to whether the research service is integrated with the library or information service and how close is the relationship. There are, however, some general principles which can be set out. 
Based on her experience of working with a number of new parliaments, Ellie Valentine ${ }^{13}$ has suggested that while there is no magic formula of how many researchers are required in an effective service as it depends largely on the nature of the institution as a whole, the number of members, the number of committees, the staffing capacity for members and committees can be factors in determining an optimal service. It would be tempting to say that there should be a ratio of $1: 5$ or $1: 10$ members or $1: 1$ researchers to committees, but the capacity of the researchers to meet the needs of the members is most essential. For new research services, it may be better to have two or three excellent researchers who can prove the value of such a service and then to gradually add well-qualified colleagues to serve a growing demand than to set up a research service based on a formula and have many people filling chairs but challenged by an inability to perform at a level required and demanding more management input.

Research services probably work best when they operate in small cooperative teams covering related policy areas, such as economic policy or social policy. On the other hand, there is a risk that these teams can become too independent and isolated from each other. This is particularly important when, as already discussed, more and more policy issues are interrelated with one another.

Research services need a range of skills, in particular, the organising, classifying and searching skills of the librarian on one hand, and the analytical and writing skills and subject knowledge of the researcher on the other. These two groups should be working cooperatively together, whatever is the organisational structure of the parliamentary service. This does not always happen and tension between the two groups is not uncommon, but is not inevitable. What matters is making the most effective use of the available resources in order to deliver the best service to parliamentarians.

${ }^{13}$ Personal communication $9^{\text {th }}$ November 2008 